\title{
The Spectrality of Nuclear Catastrophe: The Case of Chernobyl
}

\author{
Agnieszka Jelewska \\ Humanities /Art /Technology Research Centre \\ Adam Mickiewicz University \\ Poznan, Poland \\ jelewska@amu.edu.pl
}

\author{
Michał Krawczak \\ Humanities /Art /Technology Research Centre \\ Adam Mickiewicz University \\ Poznan, Poland \\ michal.krawczak@amu.edu.pl
}

\begin{abstract}
The paper is a presentation of our research focused on the ecological disaster caused by the explosion of the nuclear power plant reactor in Chernobyl in 1986, in terms of its social, cultural and artistic context. We apply the concepts of hyperobject (Morton) and hauntology (Derrida), and autoethnographic method (Adams, Jones, Ellis), in an attempt to reveal human and nonhuman agencies in the description of the catastrophe's long-term cultural consequences. In the autoethnographic and investigative-artistic part of our research we analyse our interactive installation, Post-Apocalypsis (2015), but also historical facts and private narratives. The notion of hyperobject in connection with the autoethnographic methods and investigative-artistic part of our research serves to trace the process of displacing phenomena, facts and private narratives about the Chernobyl accident in the context of time and space. The concept of hauntology enabled us to go beyond the uncovering of recurring cultural, political, social micronarrations and fear about nuclear energy in Poland.
\end{abstract}

Nuclear catastrophe. Chernobyl. Environmental studies. Autoethnography. Nonhuman agencies. Dark ecology. Hauntology. Postmemory. Interactive art. Sound design.

\section{INTRODUCTION}

The case of Chernobyl accident caused by the explosion of the nuclear power plant reactor in 1986 is very often treated by scientists as one of the worst environmental disasters, despite the fact that the resulting human losses, although tragic, were minute in comparison with catastrophes from other energy sources. As Zbigniew Jaworowski (2010b), who in 1986 was the director of the Polish Central Laboratory for Radiological Protection, puts it:

\section{Chernobyl was the worst possible catastrophe. It happened in a dangerously constructed nuclear power reactor with a total meltdown of the core and 10 days of free emission of radionuclides into the atmosphere.}

Chernobyl has therefore been analysed by scientists from various perspectives. The most important achievements were made in environmental studies, and in research on radioactivity, epidemiology and molecular biology, primarily based on data collected from Belarus, Ukraine, Russia (Savchenko 1995, Zablotska, 2016, Toronko 2017), Finland (Raska et al. 2012, Auvinen et al. 2014) and Germany (Semizoh et al. 2009, Steinhauser 2016). However, while the physical fallout from Chernobyl was grave indeed, the worst harm to the population was caused not to flesh, but to mind (Jaworowski 2010b).

Despite such statements, relatively little research has been carried out on the social reactions to the disaster, or on the impact of Chernobyl on cultural narratives about the use of nuclear energy in certain countries. In the field of social and cultural research, the consequences of the Chernobyl disaster have been treated as a stimulus for constructing a definition of modern society based on resilience strategies (Beck 1986, Giddens 1999), the processes shaping political-geographical phenomena in the post-soviet countries (Saiko 2017, Petryna 2013), the postmemory narrations (Alexievich 2005, 2016) and the political and economic manifestations of certain diseases in Belarus (Kuchinskaya 2014). However, there are no works that show the specificity of the Polish context and the social fears, beliefs and cultural consequences that were infected with that event. 
In our research, we try to identify those moments and situations that shaped the social atmosphere for understanding and relating to various aspects of atomic energy in Poland. We develop the notion of hauntology, following the proposal of Jacques Derrida (1994), and the definition of the hyperobject phenomena described by Timothy Morton (2013, 2017) to show the appearances of atomic energy and potential fear which was generated in connection to the accident in Chernobyl. We also apply our autoethnographic research on the specifically Polish context and refer to our artistic practices, analysing our work, Post-Apocalypsis (2015).

\section{CATASTROPHE AS A HYPEROBJECT}

The concept of hyperobject, as introduced by Timothy Morton (2013), is very productive for describing phenomena such as energy catastrophes and their long-term and global appearances. What Morton is trying to introduce to the studies on such phenomena is that they cannot be understood through linear processes based on the tracing of consequences. When talking about hyperobjects, we can do no more than examine their appearances, which do not express or explain the whole accident and its consequences. Morton, arriving at this conception of the hyperobject through a deep redefinition of Kant's epistemology, emphasizes that we are unable to know the whole, and thereby attributes agency to the nonhuman. As Morton (2013) writes:

\footnotetext{
As we enter the time of hyperobjects, Nature disappears and all the modern certainties that seemed to accompany it. What remains is a vastly more complex situation that is uncanny and intimate at the same time. There is no exit from this situation. Thus the time of hyperobjects is a time in which it is impossible to achieve a final distance toward the world. But for this very reason, it is also a time of irony. We realize that nonhuman entities exist that are incomparably more vast and powerful than we are, and that our reality is caught in them.
}

When adopting the scientific approach, researchers become accustomed to analysing the particular effects of nuclear disasters. In a sense, this type of approach segments the stages of a disaster according to the moment of the event, the direct and indirect effects, and the short-term and long-term consequences, with this segmentation determined by the decay of radioactive material. But nuclear disasters perceived in terms of hyperobject means that, as the situation unfolds in days and years, some aspects of the disaster are revealed in different periods, places and situations, while other aspects remain hidden.

\section{SPECTRAL AUTOETHNOGRAPHIES}

The autoethnographic method of our research (Adams et al. 2014), which is very important in the process of revealing the Chernobyl disaster's appearances of atomic energy, is not based only on the human perspective, manifested as particular postmemory and affects (Alexievich 2005, 2016), but includes the stories "told" by objects and situations, lost and hidden information, political statements, radioactive particles and radiationinduced diseases. And the spectral spatio-temporal understanding of these phenomena shows the interconnectedness of human and nonhuman subjects, as well as the non-linearity and discontinuity that bursts asunder the framework of the classically conceived history of events.

In connection with the above, another useful perspective to adapt in the research process would be the reactivation of the concept of hauntology proposed by Jacques Derrida. In 1993, he wrote the famous text that was later translated into English as Spectres of Marx, in which he referred to the end of history and showed that at the end of the 20th century, within the European political and cultural model, we as a modern society were entering the era of spectrality. As Derrida (1994) proposed:

A spectral moment, a moment that no longer
belongs to time, if one understands by this word
the linking of modalized presents (past present,
actual present: "now", future present.) We are
questioning in this instant, we are asking
ourselves about this instant that is not docile to
time, at least to what we call time. Furtive and
untimely, the apparition of the specter does not
belong to that time, it does not give time, not that
one: "Enter the ghost, exit the ghost, re-enter the
ghost" (Hamlet).

The notion of spectrality suggests that every situation, event and thought contains in itself that which is past, but also that which is to come. In this sense, Derrida suspended the linearity of history, indicating that history is actually made from the flows of the past and the future, and thus the present does not exist. The hauntological concept of the time and space of a situation's occurrence proposed by Derrida is worth comparing with the indeterminate influx of facts concerning nuclear energy disasters in social and cultural narratives. With the concept of hauntology, Derrida's description of the figure of the ghost having a disturbed ontology is also crucial. A ghost is both present and non-present. Such a treatment of ontology is fitting for both the fragments of information recurring in Polish cultural memory and for the images or private narratives related to the Chernobyl accident.

Hauntology also brings intercultural dimensions to the Polish context. In the case of the Chernobyl 
disaster, there were various cultural reactions from the European countries directly affected by the radioactive fallout, and attempts made to neutralize its negative effects. While one cultural narrative appears in the countries of the former Soviet bloc (Poland, Belarus, Ukraine), which at the time of the explosion were subordinated to totalitarian politics and had no access to reliable scientific information, there are completely different narratives in, for example, Finland (which was one of the first countries to respond to the consequences of the catastrophe) or West Germany and other countries that had free access to the scientific discussion that emerged in response to the fact of the accident.

In terms of extending the hauntological spectrum, the problem of the 1986 catastrophe should be seen as the perceived manifestation of a wider phenomenon, namely nuclear disasters in general. In the field of cultural and environmental research it is an established fact that each subsequent nuclear event directly invokes and extends narratives about previous disasters. This does not apply only to nuclear power plants, but also to the nuclear weapons tests conducted systematically, mainly by the United States and the USSR, since 1945, as well as various accidents involving nuclear cargo. In this sense, all these catastrophes, events and accidents are phenomenal manifestations of the power of atomic energy.

And finally, hauntology introduces thinking in terms of spectrality in the context of the narration of history, but also the ontology of beings who are the "speakers" (Derrida 1994, Morton 2017). Spectrality as a characteristic of the ontology of information and facts becomes a tool for rethinking the possibility of accepting the unknowing which underlies and may undermine what we think we know (Davies 2005).

Our own autoethnographic research was based on talks with our relatives and our colleagues, but also on reading blogs and unofficial information, reports, and data from different disciplines and countries, such as Belarus, Russia, Ukraine, Germany, Japan, Finland and the USA. Analyses of these materials show aspects of spectrality, destroying the linear sense of time-space, which is usually crucial in the research done on nuclear catastrophes. Fragments of our spectral autoethnographies follow below.

\subsection{Radioactive cloud}

During the days between 26 and 30 April 1986, as kids (aged 9 and 3 ) we experienced something of which we were not conscious at that time. In our country, it was mostly a warm, bright and sunny day, an ordinary Saturday in Spring. It was a perfect time for spending time with our parents in parks or playgrounds. As we can imagine it now, the weather was quite nice, and when breathing in and out you could feel springtime and fresh air in your lungs.

But from this period of time, starting on 26 April, our perception of what we used to understand as weather, air and atmosphere changed radically. Each time we breathed in and out, we became enmeshed in the hyperobject of the catastrophe. Unrecognizable at the first breath, it was glued to our clothes, hands and hair, and then it got inside our flesh. We became a part of an appearance of the atmospheric air, which was not only composed of nitrogen, oxygen, and argon, with carbon dioxide and other gases in trace amounts, but also radioactive particles, of which the most dangerous, as studies would later state, was cesium-137. The same air also became the medium for transmitting radio waves conveying political information which was at that time hidden from us. We experienced an appearance of disaster in Chernobyl through the clouds transmitted by air as a mesh of particles, which were not officially reported till 30 April.

This situation entails that the atmosphere has taken on for us, as well as for all nonhuman beings, a radically new agency - the composition of the air not only had a physical dimension, but also a military, political, medical, social and affective one. That is how, as humans and nonhumans, we have entered the dark ecology, as Timothy Morton (2016) puts it:

\begin{abstract}
meaning ecological awareness which is dark, insofar as its essence is unspeakable. It is dark, in the sense that illumination leads to a greater sense of entrapment. It is dark, because it compels us to recognize the melancholic wounds that compose us.
\end{abstract}

\subsection{The news hiding facts}

On 28 April 1986, the radiological stations in Poland noted several hundredfold increases in the radioactivity of the air (Jaworowski 2010b), and also on that day information about the explosion was officially provided by BBC radio, which, despite the attempts at suppression by the Polish authorities, was then picked up in Poland. The official information about the Chernobyl plant's explosion was not reported until 30 April. It was important to keep this information from public knowledge for as long as possible, due to the fact that 1 May was the annual International Worker's Day, which at that time was the most important propaganda festival of the entire Soviet bloc. Nobody could ever imagine that such important parades would not take place this year. The celebrations were not cancelled - but due to a fear of riots and the rebellion of citizens the information about the catastrophe was finally confirmed.

When asked about the dates of the catastrophe most of our family members said that it was revealed 
on 30 April, but in one person's account, it was 3 May, as she remembers (and is sure) that she went on the Mayday March completely unaware of the radioactive cloud. The radioactive cloud hung over Poland for several days.

Zbigniew Jaworowski (2010a), who at that time was the director of the Central Laboratory for Radiological Protection, remembers that, on seeing the radioactivity readings on 28 April, he was convinced that a nuclear war had broken out:

at the entrance to my institute in Warsaw I was greeted by a colleague with a statement, "Look, at 7:00 we received a telex from a monitoring station in northern Poland saying that the beta radioactivity of the air there is 550,000 times higher than the day before. I found a similar increase in the air filter from the station in our backyard, and the pavement here is highly radioactive." This was a terrible shock. My first thought was: A NUCLEAR WAR!

The first initial public announcement that the cloud of radiation was passing across Poland was broadcast on radio and television news on Wednesday 30 April. This was just simple information about "the malfunction" (Polish awaria) in Chernobyl, which is thousands of kilometres from Poland, and the reassurance that measures are being taken to eliminate the consequences of the accident. But the levels of anxiety in public opinion were very high. As Francis Millard (1988) reported in the Journal of Communist Studies after Polish Central Institute for Public Opinion Research:

People sought multiple sources of information, including Western broadcasts in Polish (31.8 per cent of those polled) and in foreign languages (7.8 per cent), as well as radio, television, the press, family, friends, and 'people'.

Many people with partial knowledge of the situation started to take preventive actions on their own breaking orders and disseminating fragmentary information about the threat.

\subsection{The experiment with Lugol's iodine}

During the night of 28-29 April, the Polish authorities decided to give Lugol's iodine to all children aged 017 and pregnant women, and as a result this solution was applied to $95 \%$ of Polish children (the estimated number of recipients is approximately 18,5 million people) (Jaworowski 2010b). By absorbing iodine from the fluid, the human thyroid gland was supposed to be blocked and not be susceptible to the absorption of radioactive iodine conveyed by the cloud from the Chernobyl power plant. This process of artificial immunization is a specific Polish phenomenon from that time. Years later, it was admitted that firstly the liquid was given to children too late, and secondly that it was unnecessary - this is the account offered years later by Jaworowski (2010b) himself. The relationship between the Chernobyl explosion and the administration of Lugol's iodine has itself become a fact which is subject to medical analysis. It was an extraordinary socio-medical experiment on a gigantic scale. The distribution of the fluid also revealed the social inequalities of that time. Children whose parents performed state, administrative, military and militia functions received the liquid first, as they had priority - on the night of 28 April, my (Michał's) mother recalls how the army came to our housing estate, which unofficially brought liquid to private addresses - it was the first moment of anxiety for my family. This is how we found out that something was wrong - by observing military activity through the window. $A$ race began, in which citizens tried to get a cure for their children, through acquaintances or on the black market, but most people were forced to stand in long queues in the first days of May. Many people driven by fear also decided to drink ordinary iodine, intended for the external decontamination of wounds, and this in itself was a danger to their health. The distribution of Lugol's iodine on such a scale was possible due to the fact that in the secret analyses and military simulations of the Warsaw Pact, gathered under the common codename Seven Days to the River Rhine in 1979, Poland was considered to be a prime target for a NATO nuclear attack (Jaworowski 2010b). Consequently, procedures were systematically and secretly implemented to enable citizens to survive a potential attack.

The nuclear catastrophe and its possible consequences were at first an anxiety affect, which then gradually turned into fear and became social trauma. This appearance of the atomic ghost is so powerful in Polish society that when information about the Fukushima power plant disaster appeared in 2011 - despite the lack of imminent danger - we witnessed panic and the mass purchase of iodine preparations from pharmacies.

\subsection{Cesium-137}

One of the nonhuman agents of this situation of 1986, which was - and still is - very powerful, turned out to be cesium-137. A radioactive element, whose half-life is more than 30 years, and which can persist in the ecosystem for between 180 and 300 years. From the end of April till the end of May 1986, the authorities in Poland prohibited the consumption of fresh vegetables and drinking cow's milk. This was part of an attempt to stop the direct penetration of cesium into the human body. But years later it turned out that the radioactive element is found in completely different places to what was expected. Research conducted in Germany between 1998 and 2008 revealed that the presence of cesium-137 had been found in wild boars - this is due to the fact that 
mushrooms are a staple of their diet, and mushrooms accumulate radioactive material for a long time (Semizoh et al. 2009). In subsequent years, comparative studies were carried out, referring to the Fukushima disaster (Steinhauser 2016). These studies have been carried out because, among other reasons, wild boar meat is consumed by part of the human population. These studies may shed light on a negative factor which was not taken into account in Poland during the first years after the disaster. Access to meat was rationed in Poland until 1989; its legal purchase was possible only through so-called food stamps. As a result, the illegal butcher market developed, and meat from game was a key product.

Chernobyl catastrophe has long-term cultural consequences and is often manifested as a social trauma. This is particularly true of Poland, where no large-scale studies have been carried out to examine the medical or sociological consequences of the catastrophe, which has resulted in incoherent bottom-up cultural narratives about the catastrophe and its significance. A common factor in most of these narratives is the social fear of atomic energy and its use. The reasons for the phenomenon of radiophobia Jaworowski (1999) have been identified as, among others:

- The psychological reaction to the devastation and loss of life caused by the atomic bombs dropped on Hiroshima and Nagasaki at the end of World War II.

- Psychological warfare during the cold war that played on the public's fear of nuclear weapons.

- Lobbying by fossil fuel industries.

- The interests of radiation researchers striving for recognition and budgets.

- The interests of politicians, for whom radiophobia has been a handy weapon in their power games (in the 1970s in the US, and in the 1980s and 1990s in Eastern and Western Europe and in the former Soviet Union).

- The interests of news media that profit from inducing public fear.

- The assumption of a linear, no-threshold relationship between radiation and biological effects.

Another consequence of this situation is not only scepticism with regard to new nuclear power plants (nuclear power plants planned for construction have not been completed in Poland, for example in Zarnowiec, due to waves of protests in the 1980s), but also strengthened public opinion concerning the role and functions of traditional and technologically outdated coal-fired power plants as safe methods of energy production (which, in turn, also have negative ecological consequences). The narratives that are still alive in Polish culture constitute our basic material for analysing and researching the aspect of hyperobjectivity and hauntology. From the analysis of the autoethnographic material, the gathered disaster reports show that one of the most important aspects of this event is time dislocation. Many participants of this event have problems with pinpointing facts in a specific time context, and moreover their sensation of time is disturbed. Questions thus arise about this temporary suspension. Was it caused by propaganda and the way that information about the actual state of the disaster was manipulated? Is it the effect of the passage of time and the penetration of narrative into postmemory? Or maybe it is related to the outbreak of widespread panic - which disturbed the sense of time? It is impossible to give unambiguous answers to these questions, and multi-faceted narratives about the catastrophe depend on all the abovementioned factors.

\section{POST-APOCALYPSIS}

In 2015, as the extend of our research, we prepared an interactive installation called Post-Apocalypsis for the Prague Quadriennial of Performance Design and Space. The whole process of designing the installation took us almost two years and was inextricable from our scientific research on the appearances of disasters connected to atomic energy on the autoethnographical level.

The group that worked on this project later formed the Daed Baitz collective, which operates to this day (Agnieszka Jelewska, Michał Krawczak, Paweł Janicki - media artist, Rafał Zapała - composer, Michał Cichy - architect). During the process of preparing this piece we had two very important inspirations, which in fact became not only a visual set-up for the final installation but also organized a deep structural level for interaction, user experience and very specific method of soundscape designing.

The first inspiration was the information that after the disaster in Chernobyl, four square kilometres of pine forest directly downwind of the reactor turned reddish-brown and died, thereby earning the name of the Red Forest - this fact was one of the most visually important codes during the whole process of designing the objects of the installation as broken trees, with specific technological devices placed on them. The second inspiration was the photographs of the Chernobyl catastrophe taken by Igor Kostin (2006). The unique photographs taken by Kostin in the zone of Chernobyl during the time of the radiation activity show the cloud of radioactive dust coming from the nuclear power plant. On an analog photographic plate, the photographer captured the state of the power plant after the explosion, and the work of people securing the site of the catastrophe 
(so-called liquidators). But in these pictures, radiation was also captured. Due to the high level of radiation, some of the photographs did not come out at all, the frames of the photographic film were all black and some had specific pictorial qualities - a very large grainy image or white smudge. The smudge in Kostin's photographs can be experienced in our work as multi-layered and glitchy soundscape composition.

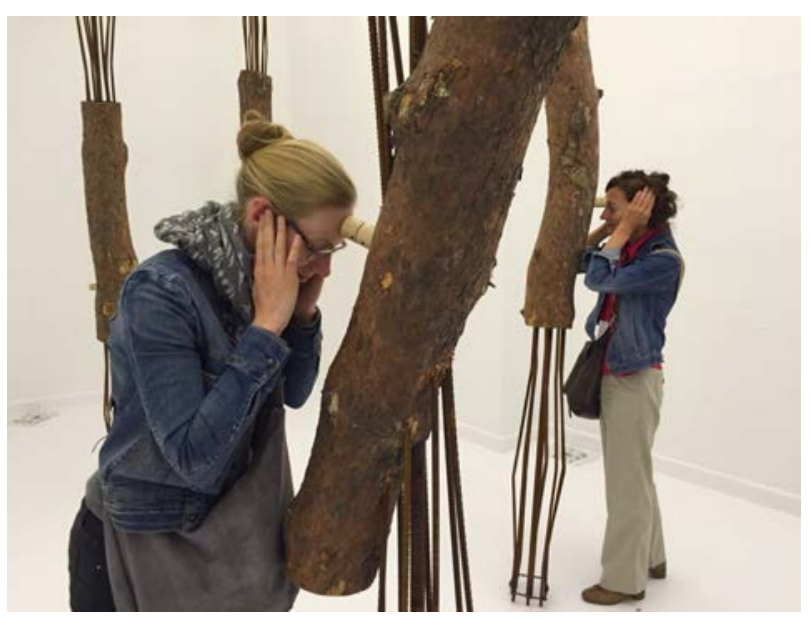

Figure 1: Post-Apocalypsis, interactive installation, 2015.

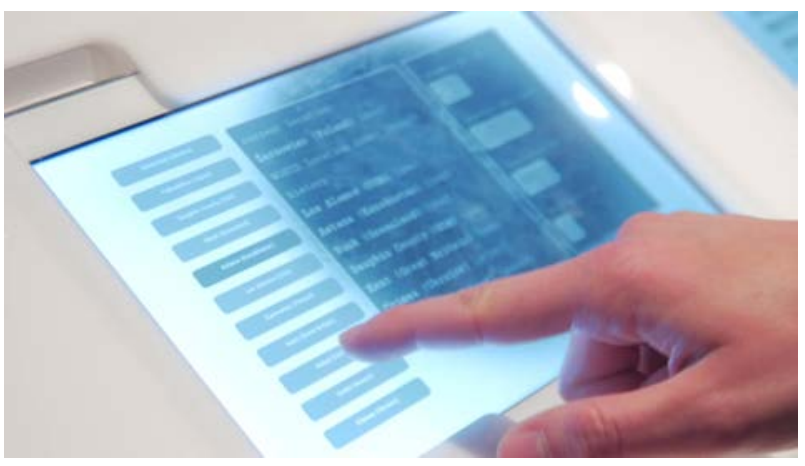

Figure 2: Post-Apocalypsis, interactive screen, 2015.

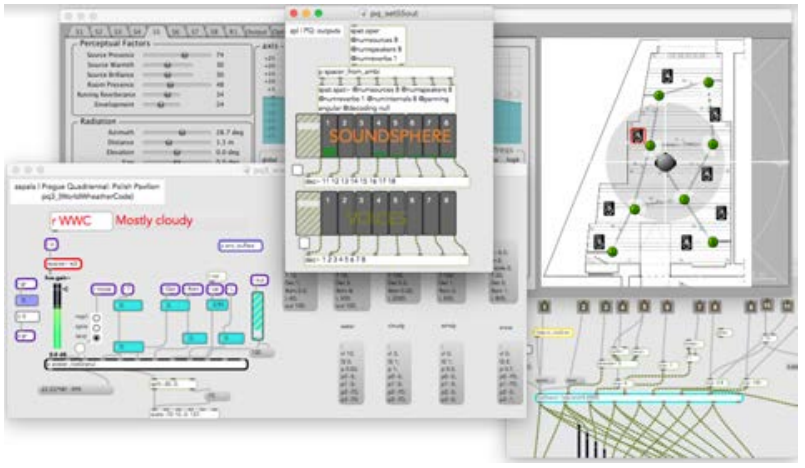

Figure 3: Post-Apocalypsis, data sonification software, 2015.
In the Post-Apocalypsis installation, participants entered a very bright white space with technologically modified trees in the centre (Figure 1). The most important part of the installation was a very dynamic soundscape which surrounded everyone in the room. The structure of sound composition was based on the process of sonifying weather data including atmospheric precipitation, temperature, wind speed and direction, air humidity, atmospheric pressure. The participants could use interactive screens (Figure 2) to choose the location where the data was collected from. The locations were connected with nuclear accidents, catastrophes or test sites, such as Chernobyl, Fukushima, Los Alamos and others. The data stream from the chosen location was sonified in real time into a granular multichannel sound composition (Figure 3). The experience of soundscape depended on the data and could be very quiet at one moment (as a soft white noise) or became suddenly very loud and glitchy. In fact, sometimes the soundscape could have been very painful for human perception.

In this sonic environment, we designed another level of hearing, which was connected to the somatic experience of bone conduction interfaces placed on the trees. After putting their heads to the interfaces (Figure 1), participants started hearing voices of Polish romantic poets (Mickiewicz, Słowacki, Norwid), not through their ears - but inside their heads. It was possible because of the bone conduction system which is based on the transmission of sound to the inner ear through the bones of the skull. The fragments of Polish romantic poetry were related to the notion of Nature and were read by a female lector with aphasia.

The soundscape of sonified data from sites connected to nuclear energy, together with the somatic hearing of the old voices, produced the uncanny and weird atmosphere of the work. The participants were in a place which was at the same time a non-place, due to the possible choice of data from different places. The atmosphere of the installation was very close to what Böhme (2017) describes post-phenomenological aesthetics. It was hybrid, spectral, and was revealed in the constant changes of the localization brought about by the participants themselves. And from our autobiographical perspective, it was very close to the atmosphere of that time in April and May 1986 when we experienced the fact that the appearances of a nuclear catastrophe are invisible, discreetly unspeakable and that they produce and infinitely open up the level of social and cultural hauntology about nuclear energy. 


\section{CONCLUSIONS}

In our article The Difficulties between art, science and technology in Poland (Jelewska \& Krawczak 2014), we described the fear of technology that exists in Polish culture, which is deeply-rooted in totalitarianism and the Cold War period and is largely identified with the communist regime. The reflections that we have been trying to present in this article complement those studies, showing the multifaceted dimensions that this fear has, and the complex assemblages it creates along with cultural narratives.

The notion of hyperobject in connection with the autoethnographic methods and investigative-artistic part of our research serves to trace the process of displacing phenomena, facts and private narratives about the Chernobyl accident in the context of time and space. The concept of hauntology enabled us to go beyond the uncovering of recurring cultural, political, social micronarrations and fear about nuclear energy in Poland. All these aspects are also manifested in the constant presence of the role of human and nonhuman agencies in the field of research on nuclear disasters.

\section{ACKNOWLEDGEMENTS}

This text is the result of our research conducted under the auspices of a grant from the Polish National Science Centre, entitled: Art as the Laboratory of New Society. The cultural consequences of post-technological turn (no: UMO2014/13/B/HS2/00508).

\section{REFERENCES}

Adams, T. E., Jones, S. H., Ellis, C. (2015) Autoethnography (Understanding Qualitative Research). Oxford: Oxford University Press.

Alexievich, S. (2005) Voices from Chernobyl: the oral history of a nuclear disaster. London: Dalkey Archive Press.

Alexievich, S. (2016) Chernobyl Prayer: A Chronicle of the Future. London: Penguin Classics.

Auvinen, A., Seppä, K., Pasanen, K., Kurttio, P., Patama, T., Pukkala, E., Heinävaara, S., Arvela, H., Verkasalo, P., Hakulinen, T. (2014) Chernobyl fallout and cancer incidence in Finland 1988-2007. International Journal of Cancer, 01 May 2014, Vol.134(9), pp. 2253-2263.

Beck, U. (1986) Risikogesellschaft. Auf dem Weg in eine andere Moderne. Frankfurt a. M.: Suhrkamp.
Böhme, G. (2017) The Aesthetics of atmosphere: ambiances, atmospheres and sensory experience of spaces. New York: Routledge.

Davis C., (2005) Hauntology, spectres and phantoms. French Studies, 59 (3), pp. 373-379.

Derrida, J. (1994) Spectres of Marx: The State of the Debts, the Work of Mourning and the New International. New York: Routledge.

Giddens, A. (1999) Risk and Responsibility. Modern Law Review, 62(1), pp. 1-10.

Herman A. F. (2014) Ghosts, vampires, zombies, and us: The undead as autoethnographic bridges. International Review of Qualitative Research, 7, pp. 327-341.

Jaworowski, Z. (1999) Radiation Risk and Ethics. Physics Today, Vol.52(9), pp. 24-29.

Jaworowski, Z. (2010a) Observations on the Chernobyl Disaster and LNT. Dose-Response, 01/2010, pp. 148-171.

Jaworowski, Z. (2010b) Observations on Chernobyl After 25 Years of Radiophobia. 21st Century Science \& Technology, Summer 2010, pp. 30-46.

Jelewska, A., Krawczak, M. (2014) The difficult relations between art, science and technology in Poland. In: Jelewska, A. (ed.) Art and technology in Poland. From cybercommunism to the culture of makers. Poznan: Adam Mickiewicz University Press, pp. 15-39.

http://artandsciencestudies.com/en/publikacje/artand-technology-in-poland/ (accessed: 6.05.2018)

Kostin, I. (2006) Chernobyl: Confessions of a Reporter. New York: Umbrage Editions.

Kuchinskaya, O. (2014) The Politics of Invisibility: Public Knowledge about Radiation Health Effects after Chernobyl. Cambridge: The MIT Press.

Morton, T. (2013) Hyperobjects: Philosophy and Ecology after the End of the World. Minnesota: University of Minnesota Press.

Morton, T. (2016) Dark ecology. For a Logic of Future Coexistence. New York: Columbia University Press.

Morton, T. (2017) Humankind. Solidarity with Nonhuman People. New York: Verso Books.

Petryna, A., (2013) Life Exposed: Biological Citizens after Chernobyl, Princeton: Princeton University Press. 
Raska, M., Saxénb, R., Ruuhijärvia, J., Arvolac, L., Järvinend, M., Koskelainenb, U., Outolab, I., Vuorinene, P. J. (2012) Short- and long-term patterns of $137 \mathrm{Cs}$ in fish and other aquatic organisms of small forest lakes in southern Finland since the Chernobyl accident. Journal of Environmental Radioactivity, 103 (2012), pp. 41-47.

Saiko, T. (2017), Environmental Crises: Geographical Case Studies in Post-Socialists Eurasia. New York: Routledge.

Savchenko, V. K. (1995) The ecology of the Chernobyl catastrophe: scientific outlines of international programme of collaborative research. Paris: UNESCO and The Parthenon Publishing Group.

Semizoh, T., Putyrskaya, V., Zibold, G., Klemt, E. (2008) Time-dependency of the Cs-137 contamination of wild boar from a region in Southern Germany in the years 1998 to 2008. Journal of Environmental Radioactivity, 100 (2009), pp. 988992.

Steinhauser, G. (2016) Cs-137 in the meat of wild boars: a comparison of the impacts of Chernobyl and Fukushima. Journal of Radioanalytical and Nuclear Chemistry, Volume 307 (3), pp 1801-1806.

Tronko, N. (2017) Thyroid neoplasia risk is increased nearly 30 years after the Chernobyl accident. International Journal of Cancer, 141(8), pp. 1585-1588.

Zablotska L. (2016) 30 years After the Chernobyl Nuclear Accident: Time for Reflection and Reevaluation of Current Disaster Preparedness Plans. Journal of Urban Health, 93(3), pp. 407-13. 